\title{
Shock Properties of High-Strength Ceramics
}

\author{
D. E. Grady \\ Sandia National Laboratories, Albuquerque, New Mexico, U.S.A.
}

\section{INTRODUCTION}

A broad class of brittle solids subjected to large amplitude shock waves can support substantial shear stress (of order 2-10 GPa) without failing due to the very limited slip systems in these materials. When failure occurs under sufficiently intense shock loading, the effect is usually observed as a wave splitting in the compressive shock front. Because of the high confining stress state associated with the failure event in the shock compression environment, it is no longer certain whether the microstructural processes of deformation are brittle or ductile. Some, although by no means sufficient, evidence supports a brittle deformation mechanism in the materials of interest [1].

Recently, a further shock-induced failure process has been suggested for brittle solids in which shear failure (possibly shear fracture) occurs separate from the compressive shock wave [2]. This phenomena has been identified as a failure wave which propagates through the solid at some distance behind the compressive shock wave, relieving the large state of shear strain. Failure waves apparently occur at shock compression amplitudes below levels previously thought to remain elastic.

The prompt failure in the compression wave front is commonly called the Hugoniot elastic limit (HEL). The HEL is interpreted as the limit of elastic response and onset of failure under dynamic uniaxial strain loading. The recently reported failure wave process, raises questions concerning this interpretation. The emerging shock wave results suggest that the HEL, rather than an elastic limit, may instead identify a transition in failure mechanism. Tentative interpretations suggest the transition is from a delayed kinetic-controlled failure process below the HEL to a prompt stresscontrolled failure above the HEL.

The present short paper focuses on two aspects of the transition regime neighboring the HEL in the compressive shock process. First, issues of rate dependence associated with prompt yield under shock compression are not well understood. We report here on observations of wave profile data on ceramics, examining the issue of elastic precursor decay. Also in this study, a number of the experimental observations of failure waves in ceramic materials (principally glass) are surveyed. Some of the principal results are summarized and dynamic failure mechanisms consistent with these results are discussed.

\section{PRECURSOR ATTENUATION IN CERAMICS}

Because of the transient times involved in the compressive shock failure and flow process, the possibility of rate-dependent strength properties of ceramic must be considered. An indication of rate-dependent strength is provided in controlled

This work was supported by the United

States Department of Energy under

Conirset DE-AC 4-94ALR5000.

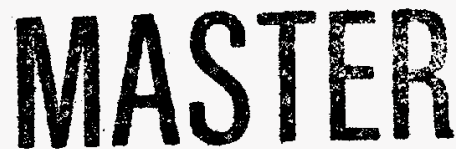




\section{DISCLAIMER}

Portions of this document may be illegible in electronic image products. Images are produced from the best available original document. 

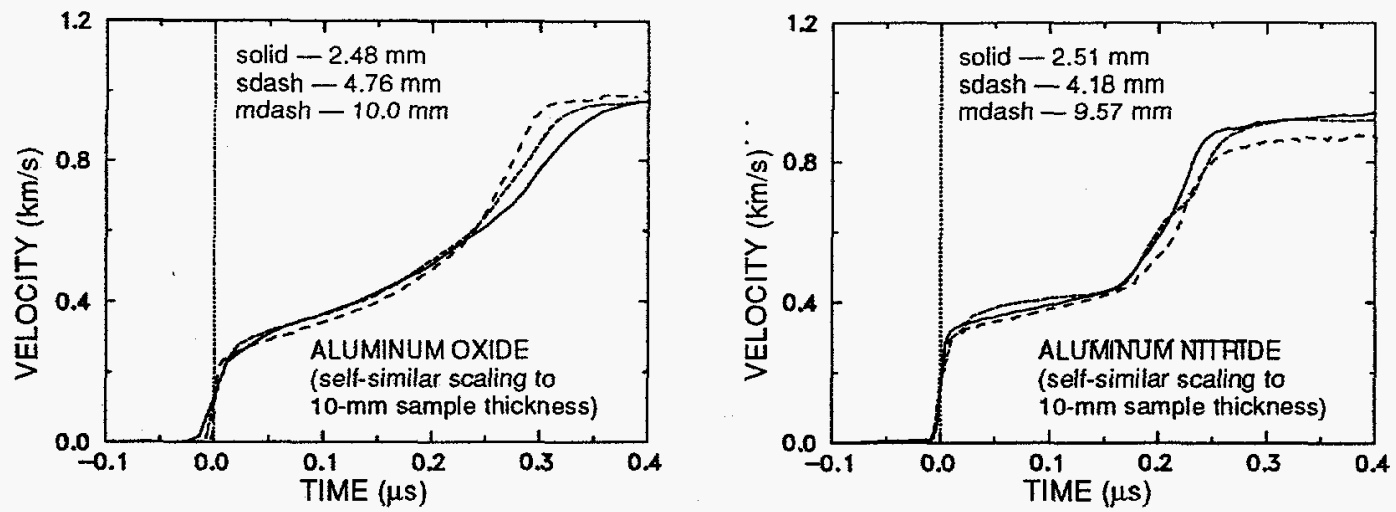

Figure 1. Precursor waves from VISAR profiles for selected ceramics [5].

shock-wave experiments through the evolution and attenuation with propagation distance of the elastic-to-inelastic transition precursor wave observed in wave-profile measurements. In the present study shock-wave data have been examined for evidence of rate-dependent precursor decay. The ceramics which have been investigated are aluminum oxide, aluminum nitride, boron carbide, silicon nitride and titanium diboride.

Studies on the rate sensitivity of ceramics, and on precursor attenuation in particular, are sparse and results to date have been contradictory. The predominant data appears to have been generated on aluminum oxide ceramic. Studies of Rosenberg et al. [3] have reported elastic precursor attenuation in aluminum oxide over sample thicknesses of a few millimeters to 25 millimeters. In contrast, measurements of Cagnoux and Longy [4] on aluminum oxide did not indicate precursor decay.

In this investigation the precursor waves of experimentally measured wave profiles on selected ceramics using velocity interferometry methods were examined for precursor decay trends [5]. Sample thicknesses were varied over the range of about $2.5 \mathrm{~mm}$ to $15 \mathrm{~mm}$. Details of the experimental method are described in Grady [6].

Representative measured elastic precursor wave profiles for aluminum oxide and aluminum nitride are shown in Figure 1. Precursor waves are plotted in a manner which scales with propagation distance and examined for self similarity. This method is believed to be a good technique for revealing precursor decay and ratedependent behavior. The profiles for aluminum oxide and aluminum nitride in Figure 1 show no evidence of precursor decay over the range of sample thicknesses tested. Similar results were found for silicon nitride and titanium diboride. Only boron carbide showed some evidence of elastic precursor decay.

The present data have been used to determine an HEL and a corresponding strain rate. A midpoint between the arrival of the elastic precursor wave and deformation shock wave was consistently established to provide the HEL amplitude. This amplitude and the time between the first and second shock waves were then used to determine a corresponding strain rate. The HEL stress and strain rate data are plotted in Figure 2. Consistent with observations of the precursor profile characteristics, with the exception of boron carbide, there is little evidence for rate dependence over the approximately half a decade of strain rate inferred from the profile measurements.

This notable lack of precursor attenuation and rate sensitivity in ceramics is surprising. Compressive failure in the shock process is believed to be a fracture-controlled mechanism and the nucleation and growth of fracture is known to be a timedependent process. Such time dependence would be expected to lead to rate-depen- 


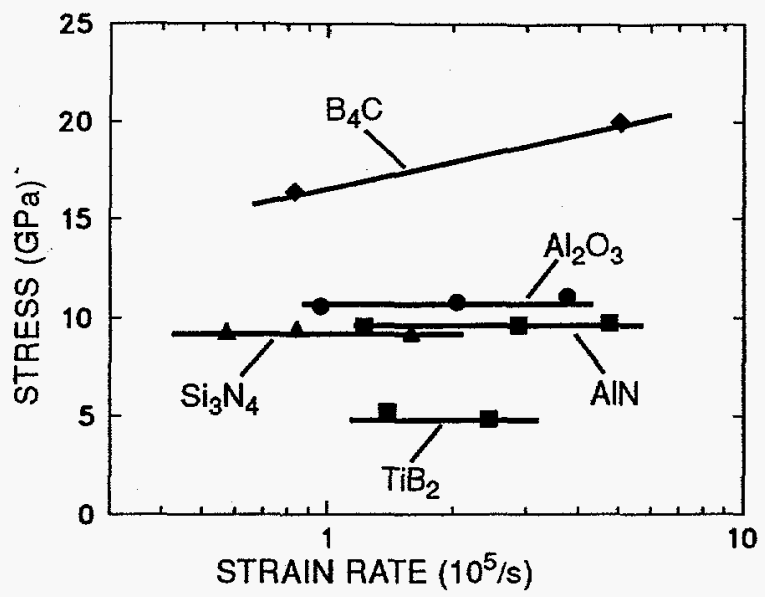

Figure 2. Hugoniot elastic limit versus strain rate data from VISAR wave profiles.

dent strength and precursor decay in ceramics. Fracture failure in brittle materials under other modes of deformation (spall, compression bar) have shown strength sensitivities on strain rate approaching a one-third power behavior. Similar rate dependence is predicted for a brittle-failure HEL mechanism [1]. The present insensitivity to strain rate raises the question of whether failure within the front of a compressive shock wave is indeed a fracture-controlled process. The present results are consistent with the conclusions of Cagnoux and Longy [4]. From their observations of negligible precursor decay in alumina, they concluded that grain plasticity was a more likely mechanism for yield in the compressive shock front than was brittle fracture.

\section{FAILURE WAVES IN CERAMICS}

The emergence and evolution of structure in a compressive shock wave such as illustrated in Figure 1 is critically dependent on the amplitude of the input stress load. If the input stress level is less than the Hugoniot elastic limit, it is expected that an elastic wave of finite amplitude will propagate in the brittle solid. This expected response has been questioned by recent experimental shock wave studies on $\mathrm{K}-2$ glass [2]. That work has provided evidence for the propagation of a delayed front of fracture following the initial elastic compression wave. This new phenomenon has been identified as a failure wave, and is presumed to be a shear fracture process which is driven by the large shear strain energy residing in the body behind the elastic uniaxial-strain compression wave.

Further evidence for failure waves has been provided by the studies of Brar et al. [7] on a similar soda-lime glass, and those of Raiser et al. [8] on an alumina-silicate glass. In the first study, transverse stress gages provided evidence for substantial increase in the transverse stress component $\sigma_{y}$ upon passage of the failure wave, significantly reducing the shear stress $\tau=\left(\sigma_{x}-\sigma_{y}\right) / 2$. In that work the tensile strength of glass behind the initial elastic shock wave, both in front of and behind the failure wave, was also tested. The tests indicated a tensile strength in excess of $3 \mathrm{GPa}$ in front of the failure wave and nearly zero strength behind, suggesting a transition to comminuted material through the failure wave.

Recently, high-speed photography has been used to examine failure wave propagation in glass. Bourne et al. [9] have used orthogonal shadowgraph photography to track the fracture front in uniaxial impact experiments on glass, revealing a coarse 
propagating fracture interface behind the shock front. Strausburger and Senf [10], using similar photographic methods, identified delayed shear fracture processes behind spherical shock fronts in glass. Earlier photographic studies of Brannon et al. [11] on crystalline quartz and glass, imaging triboluminescent failure planes behind a compressive shock front, may also have been diagnosing the failure wave process.

The early work suggested that the failure wave may be a propagating fracture front trailing the initial elastic shock wave at a velocity substantially less than the shock velocity [2]. A failure wave velocity closer to the Rayleigh wave speed has been proposed by Raiser and Clifton [12]. An alternative explanation is that the delay time between the shock wave and failure wave is governed by the kinetics of fracture nucleation and growth [5]. Incubation of the shear fracture process would initiate immediately after passage of the elastic shock front. The failure wave occurring somewhat later would manifest the catastrophic fracture growth phase.

The reported changes in the state of material upon passage of a failure wave are difficult to reconcile without rather unusual assumptions regarding material response. Several of the critical observations in glass are:

1 Velocity interferometry measurements indicate small or negligible change in particle velocity through the failure wave.

2 Transverse and normal stress measurements indicate that the stress difference $\sigma_{x}-\sigma_{y}=2 \tau$ reduces substantially during passage of the failure wave but most of the change is due to an increase in $\sigma_{y}$, with little change in $\sigma_{x}$.

3 The failure wave is reported to propagate at a velocity substantially below the longitudinal elastic velocity in glass. Values of order $2 \mathrm{~km} / \mathrm{s}$ have been inferred from experimental data. The evidence is weak, however, and any velocity up to the longitudinal sound velocity - including time and amplitude dependence - is possible.

Consider material response which leads to a failure wave with a characteristic velocity $V_{\text {failure }}$, and an accompanying loss of the stress deviator. If the volumetric compressibility behind the failure wave corresponds to full density glass, then the situation in Figure 3(a) applies. State 1 precedes the failure wave and state 2 is behind the wave. The velocity of the failure wave is determined by the chord connecting state 1 and state 2 ,

$$
V_{\text {failure }}=\sqrt{\frac{\Delta \sigma}{\rho \Delta \varepsilon}} .
$$

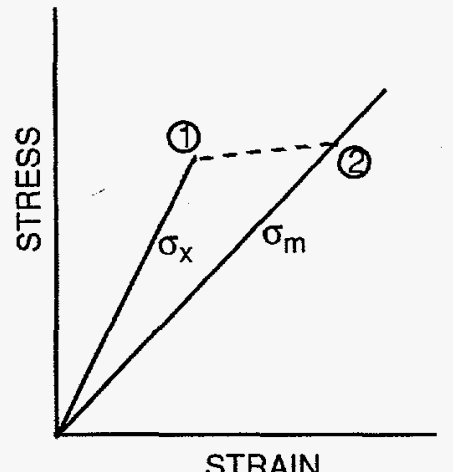

(a)

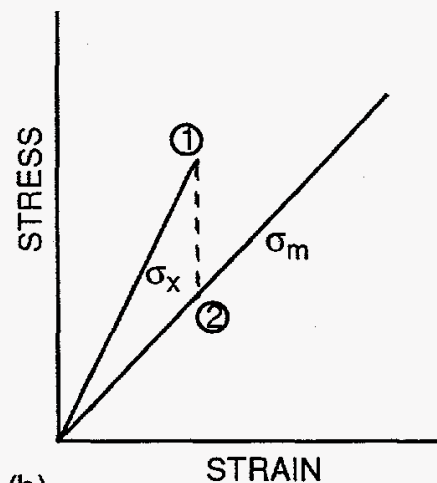

(b)

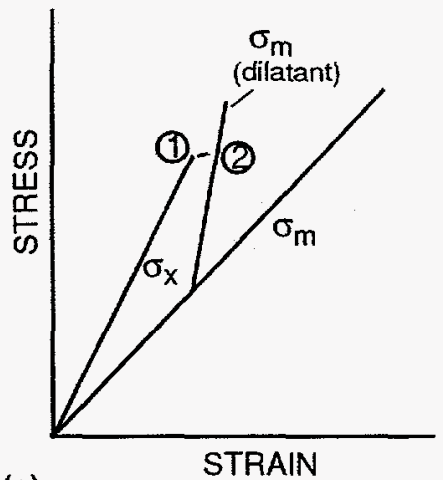

(c)

Figure 3. Transition states for failure waves in brittle solids. In each example the shock state at point one is below the Hugoniot elastic limit. $\sigma_{\mathrm{x}}$ and $\sigma_{\mathrm{m}}$ represent uniaxial strain and mean stress loading paths, respectively. 
The difficulty with this explanation is that a substantial increase in particle velocity ( $\Delta u=\Delta \varepsilon V_{\text {failure }}$ ) is not consistent with the first observation.

A second possibility is that material behavior through the failure wave represents catastrophic relaxation of shear stress due to time-dependent fracture nucleation and growth. Consider the possibility in Figure 3(b) of complete relaxation of the stress deviator at constant strain through the failure wave. To achieve the volumetric compression curve of fully dense glass (state 2 in Figure 3(b)), a substantial drop in $\sigma_{x}$ through the failure wave is required - approximately twice the increase in $\sigma_{y}-$ which is not consistent with the first observation.

A possible material behavior, which could be consistent with the three experimental observations is illustrated in Figure 3(c). An alternative pressure (mean stress) versus volume curve is initiated due to shear fracture induced dilatancy in the failure wave. The process could lead to a fixed failure wave velocity, with small changes in particle velocity and longitudinal stress through the failure wave. The dilatant void volume required to accommodate the behavior can be estimated. A pressure change is related to volumetric lattice strain $v_{\text {lat }}$ through the bulk modulus $K$ according to,

$$
d p=-K \frac{d v_{l a t}}{v_{l a t}},
$$

However, if dilatant void volume $d v_{d i l}$ is introduced, the total specific volume change is $d v=d v_{l a t}+d v_{d i l}$ and, assuming for simplicity, a constant strain process through the failure wave, $d v=0$,

$$
\frac{d v_{d i l}}{v} \cong \frac{d p}{K}
$$

If it is further assumed that $d \sigma_{x}=0$ and that $\sigma_{x}=\sigma_{y}$ after passage of the failure wave, then $d p \cong 4 \tau / 3$, where $\tau$ is the shear stress in the elastic state preceding the failure wave, and

$$
\frac{d v_{d i l}}{v} \cong \frac{4}{3} \frac{\tau}{K}
$$

For glass shocked to about $5 \mathrm{GPa}$ on the Hugoniot, $\tau=1.7 \mathrm{GPa}, K \approx 56 \mathrm{GPa}$, predicting a dilatant strain of about $4 \%$. The complete transfer of elastic shear strain energy to dilatant strain energy yields a comparable result.

\section{DISCUSSION}

The recent evidence for failure waves suggests that the elastic states achieved under shock compression, in at least some of the high-strength solids, may indeed be transient. Shear failure and relaxation of the elastic strain state does occur, but it is delayed. Kinetics of the fracture process would appear to be a likely explanation for the delayed failure. Kinetic times are expected to be a strong function of the amplitude of elastic strain - achieving zero at the HEL stress. Shock-wave profile evidence suggests, for impact amplitudes in excess of the HEL, prompt rateindependent shear failure. Candidate failure mechanisms above the HEL include dislocation plasticity or stress-controlled fracture. The results argue for an interpretation of the HEL in the shock compression of brittle solids as a transition in the mechanisms of failure. 


\title{
5. REFERENCES
}

[1] D. E. Grady, Dynamic Failure of Brittle Solids, in Fracture and Damage of Quasi-brittle Structures, edited by Z. P. Bazant et al., E\&FN Spon (1994) pp.259-273.

[2] G. T. Kanel, V. Rasoranov, V. E. Fortov, Failure Waves and Spallations in Homogeneous Brittle Material, in Shock Compression of Condensed Matter-1991, edited by S. C. Schmidt et al., Elsevier (1992) pp. 451-454.

[3] Z. Rosenberg, N. S. Brar, S. J. Bless, Elastic Precursor Decay in Ceramics as Determined with Manganin Stress Gauges, in 2rd International Conference on Mechanical and Physical Behavior of Materials under Dynamic Loading, les Editions des Physique (1988) pp. 707-711.

[4] J. Cagnoux, and F. Longy, Is the Dynamic Strength of Alumina Rate Dependent, in Shock Compression of Condensed Matter - 1987, edited by S. C. Schmidt and N. C. Holmes, Elsevier (1987) pp. 293-296.

[5] D. E. Grady, Dynamic Properties of Ceramic Materials, Sandia National Laboratories Report, in publication (1995).

[6] D. E.Grady, Shock-Compression Properties of Ceramics, in Recent Trends in High Pressure Research, edited by A. K. Singh, Oxford and IBH (1992) pp. 641-650.

[7] N. S. Brar, S: J. Bless, Z. Rosenberg, Impact-Induced Failure Waves in Glass Bars and Plates, Appl. Phys. Lett., Vol. 59 (1991) pp. 3396-3398.

[8] G. V. Raiser, J. L. Wise, R. J. Clifton, D. E. Grady, D. E. Cox, Plate Impact Response of Ceramics and Glasses, J. Appl. Phys., Vol. 75 (1994) pp. 3862-3872.

[9] N. K. Bourne, Z. Rosenberg, Y. Mebar, T. Obara, J. E. Field, A High-Speed Photographic Study of Fracture Wave Propagation in Glasses, in Proceedings of EuroDYMAT 94 - International Conference of Mechanical and Physical Behavior of Materials under Dynamic Loading, Oxford England, September 26-30, (1994) in preparation.

[10] H. Senf, E. Strausburger, H. Rothenhausier, Stress Wave Damage and Fracture in Impacted Glasses, in Proceedings of EuroDYMAT 94 - International Conference of Mechanical and Physical Behavior of Materials under Dynamic Loading, Oxford England, September 26-30, (1994) in preparation.

[11] P. J. Brannon, C. Konrad, R. W. Morris, E. D. Jones, J. R. Asay, Studies of the Spectral and Spatial Characteristics of Shock-Induced Luminescence from X-Cut Quartz, J. Appl. Phys., Vol. 54 (1983) pp. 6374-6381.

[12] G. V Raiser and R. J. Clifton, Failure Waves in Uniaxial Compression of an Aluminosilicate Glass, in High Pressure Science and Technology - 1993, edited by S. C. Schmidt et al., AIP Press (1994) pp. 1039-1042.

\section{DISCLAIMER}

\begin{abstract}
This report was prepared as an account of work sponsored by an agency of the United States Government. Neither the United States Government nor any agency thereof, nor any of their employees, makes any warranty, express or implied, or assumes any legal liability or responsibility for the accuracy, completeness, or usefulness of any information, apparatus, product, or process disclosed, or represents that its use would not infringe privately owned rights. Reference herein to any specific commercial product, process, or service by trade name, trademark, manufacturer, or otherwise does not necessarily constitute or imply its endorsement, recommendation, or favoring by the United States Government or any agency thereof. The views and opinions of authors expressed herein do not necessarily state or reflect those of the United States Government or any agency thereof.
\end{abstract}

